\title{
Eosinophilic and non-eosinophilic COPD patients with chronic respiratory failure: neutrophil-to- lymphocyte ratio as an exacerbation marker
}

This article was published in the following Dove Press journal:

International Journal of COPD

Number of times this article has been viewed

\author{
Eylem Acartürk Tunçay \\ Zuhal Karakurt \\ Emine Aksoy \\ Cuneyt Saltürk \\ Sinem Gungor \\ Nezihe Ciftaslan \\ Ilim Irmak \\ Dilek Yavuz \\ Birsen Ocakli \\ Nalan Adıgüzel
}

Respiratory Intensive Care Unit, Sureyyapașa Chest Diseases and Thoracic Surgery Education and Research Hospital, University of Health Sciences, Istanbul, Turkey
Correspondence: Zuhal Karakurt Sureyyapașa Chest Diseases and Thoracic Surgery Education and Research Hospital, University of Health Sciences, Basıbuyuk District, Maltepe, Istanbul 34854, Turkey Tel +90 5326466590 Email zuhalkarakurt@hotmail.com
Aim: Increased dyspnea, sputum volume, and purulence are subjective symptoms in COPD patients. To diagnose COPD exacerbations with chronic respiratory failure (CRF) and to assess the requirement for antibiotic treatment, physicians require more objective criteria. We aimed to investigate whether neutrophil-to-lymphocyte ratio (NLR) can be used as an infectious exacerbation marker in COPD patients with CRF.

Patients and methods: This retrospective cross-sectional study was performed in the intensive care outpatient clinic of a tertiary training hospital between 2014 and 2015. Patients admitted with CRF due to COPD and who had complete blood count (CBC) results were enrolled. CBC results and C-reactive protein (CRP) levels were obtained from the hospital online database. The "modified exacerbation model (MEM)" was defined as follows: exacerbation A, leukocytes $\geq 12,000 / \mathrm{mm}^{3}$, CRP $>10 \mathrm{mg} / \mathrm{dL}$; exacerbation B, leukocytes $\geq 10,000 / \mathrm{mm}^{3}$, CRP $>10 \mathrm{mg} / \mathrm{dL}$; exacerbation C, leukocytes $\geq 10,000 / \mathrm{mm}^{3}, \mathrm{CRP}>8 \mathrm{mg} / \mathrm{dL}$; exacerbation D, leukocytes $\geq 10,000 / \mathrm{mm}^{3}, \mathrm{CRP}>5 \mathrm{mg} / \mathrm{dL}$. The cutoff value of NLR was defined for each model. Patients were split into two groups based on the NLR cutoff value according to the "NLR exacerbation model" and further subgrouped according to peripheral eosinophil percentage (eosinophils $\geq 2 \%$ and $<2 \%$ ) and compared with the MEM.

Results: A total of 1,066 COPD patients (430 females, $40.3 \%$ ), with a mean age of $66 \pm 13$ years, were included. A NLR cutoff value of 3.54 (NLR $\geq 3.54, n=366,34 \%$ ) showed the highest sensitivity and specificity for model A $(78 \%, 69 \%)$, model B $(63 \%, 71 \%)$, model C $(61 \%$, $72 \%)$, and model D $(58 \%, 72 \%)$. Peripheral eosinophilia ( $\mathrm{PE} \geq 2 \%$ ) was present in 48 patients (4.5\%). The ratio of patients with $\mathrm{PE}<2 \%$ in the NLR $\geq 3.54$ group was significantly higher in the MEM $(P<0.001)$.

Conclusion: The NLR presents an attractive option as an exacerbation marker in COPD patients with CRF due to its simplicity and cost-effectiveness. In COPD patients with CRF, where the NLR is $\geq 3.54$, PE levels are $<2 \%$, and subjective symptoms are present, antibiotic treatment should be considered.

Keywords: COPD, exacerbation, chronic respiratory failure, neutrophil-to-lymphocyte ratio, peripheral eosinophilia

\section{Introduction}

An exacerbation of COPD with chronic respiratory failure (CRF) is the primary issue affecting morbidity and mortality. ${ }^{1}$ Infection of the tracheobronchial tree and air pollution constitute two-thirds of the causes of COPD exacerbation. ${ }^{2}$ Antibiotic therapy and corticosteroids are the cornerstone treatment of acute exacerbations of COPD (AECOPD). ${ }^{3}$ 
Although the majority of COPD exacerbations have an infectious origin, one-third of the causes of exacerbation remain undetermined. ${ }^{2}$ Current guidelines recommend the use of antibiotics for COPD exacerbations based on the Anthonisen criteria (ie, an increase in at least one of the following symptoms: dyspnea, sputum volume, and sputum purulence). ${ }^{3,4}$ Although this assessment method is relatively simple, it has not been appropriately validated. ${ }^{5}$ Patients with more severe airflow obstruction have statistically more severe dyspnea. ${ }^{6}$ Since the severity of COPD increases, and forced expiratory volume in 1 second $\left(\mathrm{FEV}_{1}\right)$ decreases, patients seem to be permanently dyspneic. Purulent sputum is a subjective term and is not defined further; hence, planning the treatment on this observation may also be partly empirical. The color of sputum is also insufficient to decide whether the patient should receive treatment or not. ${ }^{7}$

In clinical practice, there are various situations where clinicians require objective criteria to base their decision to commence antibiotic therapy. Inflammatory markers such as C-reactive protein (CRP), peripheral blood neutrophil-tolymphocyte ratio (NLR), and the presence of eosinophilia can have promising results for initial COPD exacerbation treatment and prognosis. ${ }^{8-14}$ Recent studies showed that up to $45 \%$ of patients with AECOPD had an eosinophilic inflammation. ${ }^{15-18}$ Very recently, a few studies showed that the degree and value of peripheral blood eosinophilia (PBE cutoff of $2 \%$ ) in COPD patients may help physicians when deciding on steroid or antibiotic management. ${ }^{18-20}$ Factors affecting the decision to manage COPD exacerbations with steroids, antibiotics, or a combination of both are not clear. Besides the clinical findings in patients with severe COPD who have at least one admission to the intensive care unit (ICU), who are dyspneic and produce frequent dark-colored sputum, an objective assessment of infectious markers is required.

We hypothesized that both peripheral blood NLR and the percentage of eosinophils may help the physician to make a decision on steroid or antibiotic treatment, or a combination of both, in patients with AECOPD. The current study also developed an acute exacerbation model to recognize AECOPD.

\section{Patients and methods}

This retrospective, observational, cross-sectional study was conducted in a tertiary teaching hospital for chest diseases and thoracic surgery center, level III respiratory ICU outpatient clinic, between January 2013 and November 2015. The "CRF outpatient clinic" was designed to follow up patients receiving long-term oxygen therapy (LTOT), noninvasive mechanical ventilation (NIMV), and invasive mechanical ventilation (IMV), for different diseases, eg, kyphoscoliosis, obesity hypoventilation, obstructive sleep apnea, neuromuscular diseases, bronchiectasis, COPD, asthma, tuberculosis sequelae, and tracheostomized patients. About 1-, 3-, and 6-month follow-ups were performed routinely after discharge from ICU.

The study was approved by the University of Health Sciences Sureyyapaşa Chest Diseases and Thoracic Surgery Education and Research Hospital Local Ethical Committee (July 27, 2015, number 6), and was in accordance to the Declaration of Helsinki. As informed consent from patients to review their medical records was not obtained, patient data were de-identified.

\section{Patients}

Subjects previously diagnosed with COPD (ICD coding J44) according to the international/national guidelines and who were admitted to the ICU outpatient clinic due to CRF (receiving domiciliary LTOT and NIMV) were included in the study (Figure 1). ${ }^{21,22}$ All patients were grouped according to their level of peripheral eosinophilia (PE) and NLR cutoff values.

The cutoff values of NLR were evaluated to determine the modified exacerbation model (MEM). COPD patients with CRF receiving domiciliary LTOT and/or NIMV were grouped into the "stable" or "acute exacerbation" group according to the NLR cutoff values (Figure 2).

Furthermore, each group was stratified into two subgroups based on the presence of PBE (Figure 2). ${ }^{19}$

\section{Definitions}

Diagnosis of COPD: the COPD diagnosis was established by a pulmonologist who evaluated airflow obstruction on spirometry (ie, $\mathrm{FEV}_{1} \leq 70 \%$ predicted and $\mathrm{FEV}_{1}$ and forced

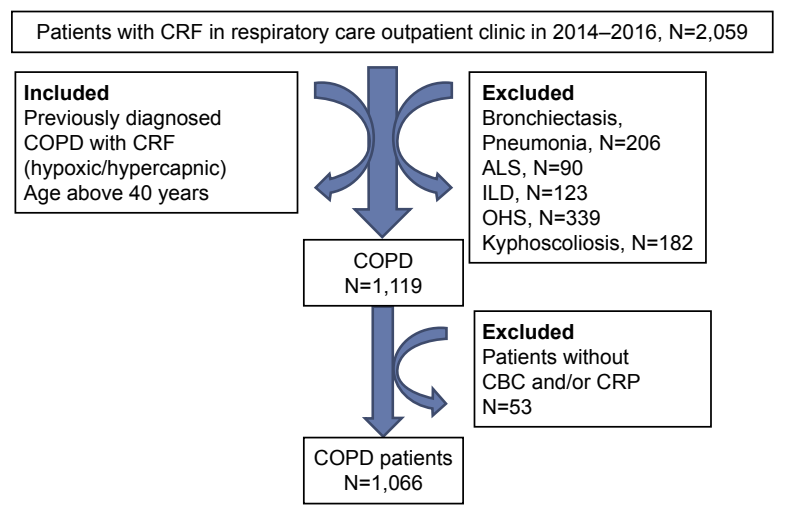

Figure I Flowchart of patient enrollment.

Abbreviations: ALS, amyotrophic lateral sclerosis; $\mathrm{CBC}$, complete blood count; CRF, chronic respiratory failure; CRP, C-reactive protein; ILD, interstitial lung disease; OHS, obesity hypoventilation syndrome. 


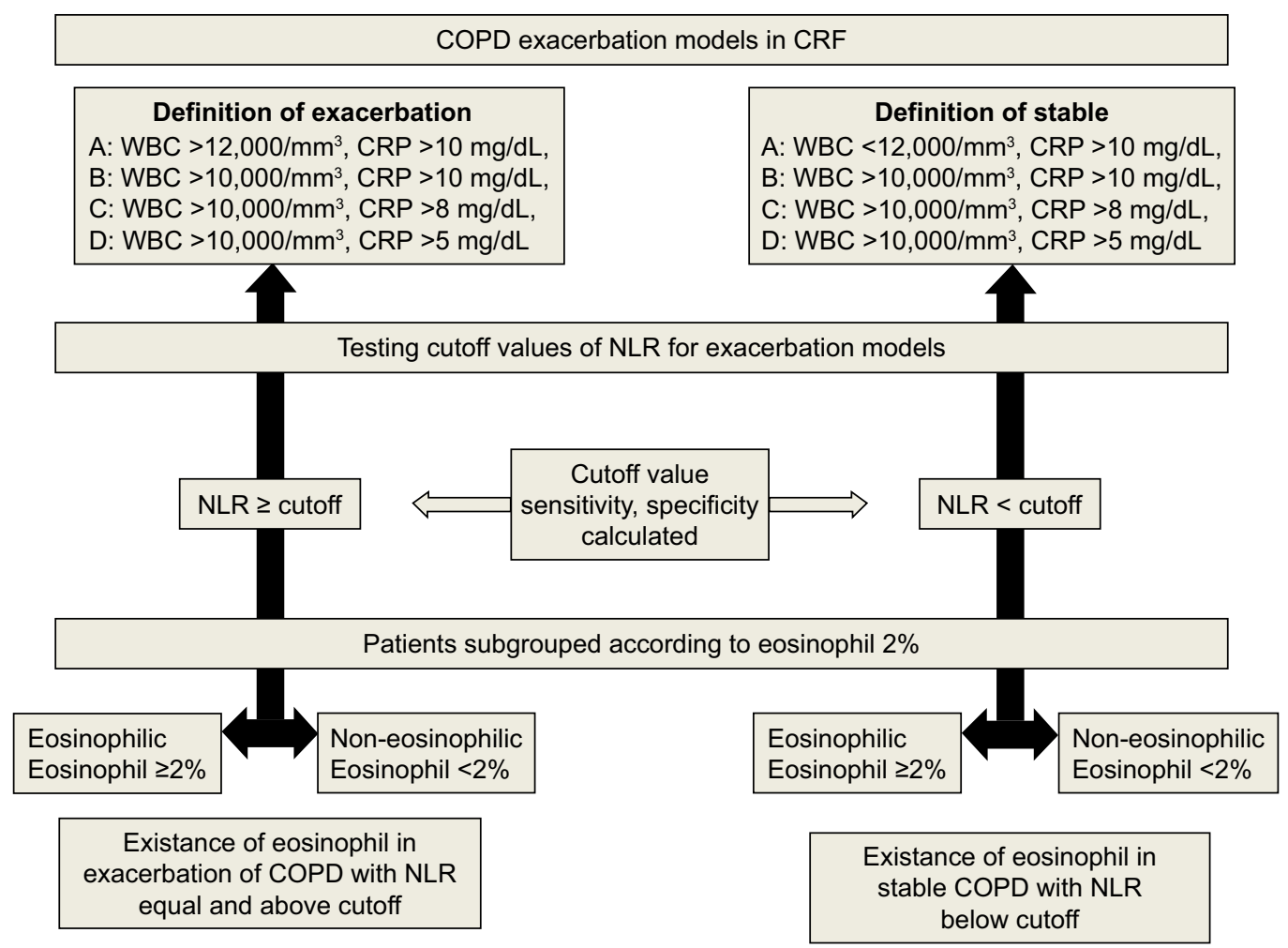

Figure 2 Flowchart of MEMs in COPD patients with CRF.

Notes: Exacerbation and stable groups were defined by using MEMs. Patients were grouped into two according to NLR cutoff value and evaluated for the presence of PBE. Abbreviations: CRF, chronic respiratory failure; CRP, C-reactive protein; MEM, modified exacerbation model; NLR, neutrophil-to-lymphocyte ratio; PBE, peripheral blood eosinophilia; WBC, white blood cell.

vital capacity $[\mathrm{FVC}]$ ratio $\leq 70 \%$ ) in patients with a compatible history for COPD. ${ }^{3}$

\section{Definition of AECOPD}

The exacerbation of COPD was defined as acute change in a patient's respiratory symptoms that is beyond normal variability and change in therapy. The majority of COPD exacerbations have an infectious origin. The COPD exacerbation due to an infectious origin was defined by the Anthonisen criteria (ie, an increase in at least one of the following symptoms: dyspnea, sputum volume, and sputum purulence), CRP, and leukocyte values. ${ }^{3,4}$ These data were obtained from patient files by two pulmonologists working in ICU outpatient clinic. Chest X-ray was performed on the patients who had further symptoms of pneumonia. Patients diagnosed with pneumonia were excluded from the study.

\section{Definition of CRF}

According to arterial blood gas (ABG) values, chronic hypercapnic and hypoxemic respiratory failure was defined as $\mathrm{pH}$ above 7.45, $\mathrm{PaCO}_{2}$ above $45 \mathrm{mmHg}$, and $\mathrm{PaO}_{2}$ below $55 \mathrm{mmHg}$ if patients were in clinically stable state..$^{23,24}$

\section{MEMs}

To objectively evaluate whether a COPD exacerbation was due to an infection, four COPD exacerbation models were defined. MEMs were designed according to the leukocyte count and CRP values. Subjects who fulfilled these criteria were accepted as having an infection that had caused the exacerbation, while exacerbation in those patients who did not fulfill the criteria was believed to have a noninfectious origin. In the exacerbation model, CRP values of 10,8 , and $5 \mathrm{mg} / \mathrm{dL}$ were defined according to previous studies. ${ }^{25-27}$ An upper limit for leukocyte values was defined as $12,000 / \mathrm{mm}^{3}$ according to the systemic inflammatory response syndrome (SIRS) criteria, and $10,000 / \mathrm{mm}^{3}$ was defined as the upper limit of normal. The four exacerbation models are summarized as follows:

- Exacerbation model A: leukocytes $\geq 12,000 / \mathrm{mm}^{3}$, CRP $>10 \mathrm{mg} / \mathrm{dL}$. Leukocyte levels $>12,000 / \mathrm{mm}^{3}$ are accepted as one of the systemic inflammatory response criteria, and a CRP of $10 \mathrm{mg} / \mathrm{dL}$ and above is accepted as the highest level of infection.

- Exacerbation model B: leukocytes $\geq 10,000 / \mathrm{mm}^{3}$, CRP $>10 \mathrm{mg} / \mathrm{dL}$. Leukocyte levels of $10,000 / \mathrm{mm}^{3}$ represent the upper limit of normal, and CRP $>10 \mathrm{mg} / \mathrm{dL}$ is accepted as the highest level of infection. 
- Exacerbation model C: leukocytes $\geq 10,000 / \mathrm{mm}^{3}$, CRP $>8 \mathrm{mg} / \mathrm{dL}$. Leukocyte levels of $10,000 / \mathrm{mm}^{3}$ represent the upper limit of normal, and a CRP of $8 \mathrm{mg} / \mathrm{dL}$ is accepted as the cutoff level for COPD exacerbation.

- Exacerbation model D: leukocytes $\geq 10,000 / \mathrm{mm}^{3}$, $\mathrm{CRP}>5 \mathrm{mg} / \mathrm{dL}$. These represent the upper limits of normal for both values.

\section{PBE}

PBE defined by an eosinophil count $\geq 2 \%$ was accepted as eosinophilic COPD exacerbation. If the peripheral blood eosinophil count was $<2 \%$, it was defined as a non-eosinophilic exacerbation. ${ }^{19}$

\section{NLR}

This marker of inflammation was obtained by dividing the absolute count of neutrophils by lymphocytes in the complete blood count (CBC).

\section{Spirometry test}

Spirometry was performed according to the recommendations of the American Thoracic Society guidelines. ${ }^{25}$ The patient's spirometry data from the previous year were obtained manually from their outpatient files.

\section{Data recorded}

Patient characteristics, CBC values, CRP values, spirometry values, and $A B G$ values were collected from the online hospital database. NLR values were calculated.

Total leukocyte, neutrophil, eosinophil, lymphocyte, and platelet counts were determined using the Coulter LH 780 Hematology Analyzer (Beckman Coulter, Inc., Brea, CA, USA). CRP was determined by the nephelometry method using a BN II System (Siemens, Munich, Germany). The normal range of CRP is $0-5 \mathrm{mg} / \mathrm{dL}$.

\section{Statistical analyses}

Descriptive analysis was used to investigate patient demographics and clinical data. The SPSS portable 20.0 package program (IBM Corporation, Armonk, NY, USA) was used for analysis. Groups were compared using the Mann-Whitney $U$-tests for nonparametric continuous variables, or Student's $t$-tests for parametric continuous variables. Chi-square tests were employed for dichotomous variables. The median with interquartile range was employed for nonparametric continuous variables, and mean $\pm \mathrm{SD}$ was used for parametric continuous variables. Count and percentage were used when applicable. Receiver operating characteristic (ROC) curves were constructed, and the area under the curve (AUC) was obtained to determine the optimal cutoff values of the NLR for the exacerbation models. If the $P$-value was $<0.05$, it was accepted as statistically significant.

\section{Results}

Of the 2,059 assessed, 1,066 COPD patients with CRF were enrolled in the study (Figure 1). All the study patients who required domiciliary LTOT and/or NIMV after discharge from ICU were referred to the ICU outpatient clinic. As such, the study group could be assumed to be in the severe stage of COPD. The mean age of the patients was $66 \pm 13$ years, and $430(40.3 \%)$ were female. Table 1 summarizes the patients' demographics, smoking history, use of domiciliary LTOT and/or NIMV, CBC, spirometry, and ABG.

Table I Characteristics of COPD patients with CRF

\begin{tabular}{|c|c|c|}
\hline Variables & $\mathbf{N}$ & Values \\
\hline Gender, male (n, \%) & 636 & 60 \\
\hline Age, median (IQR) (years) & 1,066 & $67(60-75)$ \\
\hline BMI, median (IQR) $\left(\mathrm{kg} / \mathrm{m}^{2}\right)$ & 728 & $26(21-33)$ \\
\hline Cigarette, median (IQR) (pack/year) & 223 & $45(33-70)$ \\
\hline LTOT (n, \%) & 392 & 65 \\
\hline Home noninvasive ventilation ( $\mathrm{n}, \%)$ & 266 & 44 \\
\hline \multicolumn{3}{|l|}{ ABGs } \\
\hline $\mathrm{pH}$, mean $\pm \mathrm{SD}$ & 423 & $7.39 \pm 0.04$ \\
\hline $\mathrm{PaCO}_{2}$, mean $\pm \mathrm{SD}(\mathrm{mmHg})$ & 423 & $49 \pm 8$ \\
\hline $\mathrm{PaO}_{2} / \mathrm{FiO}_{2}$, median $(\mathrm{IQR})$ & 395 & $300(265-357)$ \\
\hline $\mathrm{HCO}_{3}$, median (IQR) (mmol) & 423 & $29(27-32)$ \\
\hline $\mathrm{SaO}_{2}$, mean $\pm \mathrm{SD}(\%)$ & 399 & $92 \pm 5$ \\
\hline \multicolumn{3}{|l|}{ Spirometry values } \\
\hline $\mathrm{FEV}_{1}$, median $(\mathrm{IQR})(\mathrm{mL})$ & 355 & $730(570-970)$ \\
\hline $\mathrm{FEV}_{1}$, median (IQR) (\%) & 345 & $31(23-43)$ \\
\hline FVC, median (IQR) (mL) & 355 & $1,320(1,005-1,730)$ \\
\hline FVC, median (IQR) (\%) & 355 & $43(32-53)$ \\
\hline $\mathrm{FEV}_{\mathrm{I}} / \mathrm{FVC}$, median (IQR) (\%) & 355 & $57(49-65)$ \\
\hline \multicolumn{3}{|l|}{$\mathrm{CBC}$} \\
\hline Leukocyte, mean $\pm S D\left(\times 10^{9} / L\right)$ & 1,066 & $8.42 \pm 2.76$ \\
\hline Neutrophil, mean \pm SD $\left(\times 10^{9} / \mathrm{L}\right)$ & 1,066 & $5.7 \pm 2.5$ \\
\hline Neutrophil, mean \pm SD (\%) & 1,066 & $66 \pm 10$ \\
\hline Lymphocyte, median (IQR) $\left(\times 10^{9} / \mathrm{L}\right)$ & 1,066 & $1.78(1.39-2.23)$ \\
\hline Lymphocyte, mean \pm SD (\%) & 1,066 & $23 \pm 8$ \\
\hline Eosinophil, median (IQR) $\left(\times 10^{9} / \mathrm{L}\right)$ & 1,066 & $0.15(0.09-0.23)$ \\
\hline Eosinophil, median (IQR) (\%) & 1,066 & $2.02(1.23-3.10)$ \\
\hline Erythrocyte, mean $\pm S D\left(\times 10^{12} / L\right)$ & 1,066 & $4.67 \pm 0.72$ \\
\hline Hemoglobin, mean $\pm S D(g / d L)$ & 1,066 & $13.2 \pm 2.1$ \\
\hline Hct, mean \pm SD (\%) & 1,066 & $41 \pm 6$ \\
\hline $\mathrm{MCV}$, mean $\pm \mathrm{SD}(\mathrm{fL})$ & 1,066 & $87 \pm 7$ \\
\hline Platelet, mean $\pm S D\left(\times 10^{9} / L\right)$ & 1,062 & $247 \pm 92$ \\
\hline NLR, median (IQR) & 1,066 & $2.90(2.12-3.99)$ \\
\hline CRP, median (IQR) (mg/dL) & 1,042 & $9.9(3.6-17.7)$ \\
\hline
\end{tabular}

Abbreviations: $A B G$, arterial blood gas; $B M I$, body mass index; $C B C$, complete blood count; CRF, chronic respiratory failure; CRP, C-reactive protein; FEV , forced expiratory volume in I second; FVC, forced vital capacity; Hct, hematocrit; IQR, interquartile range; LTOT, long-term oxygen therapy; MVC, mean corpuscular volume; NLR, neutrophil-to-lymphocyte ratio; PLT, platelet. 
Table 2 Patient distribution in MEMs

\begin{tabular}{lll}
\hline Models & Attack, N (\%) & Stable, N (\%) \\
\hline Exacerbation model A & $73(7)$ & $993(93)$ \\
Exacerbation model B & $173(16)$ & $893(84)$ \\
Exacerbation model C & $192(18)$ & $874(82)$ \\
Exacerbation model D & $218(20)$ & $848(80)$ \\
\hline
\end{tabular}

Notes: Model A: WBC $\geq 12,000 / \mathrm{mm}^{3}, C R P>10 \mathrm{mg} / \mathrm{dL}$ for attack group $\mathrm{WBC}<12,000 / \mathrm{mm}^{3}, \mathrm{CRP}<10 \mathrm{mg} / \mathrm{dL}$ for stable group. Model $\mathrm{B}: \mathrm{WBC} \geq 10,000 / \mathrm{mm}^{3}$, CRP $>10 \mathrm{mg} / \mathrm{dL}$ for attack group;WBC $<10,000 / \mathrm{mm}^{3}, \mathrm{CRP}<10 \mathrm{mg} / \mathrm{dL}$ for stable group. Model C:WBC $\geq 10,000 / \mathrm{mm}^{3}, \mathrm{CRP}>8 \mathrm{mg} / \mathrm{dL}$ for attack group;WBC $<10,000 / \mathrm{mm}^{3}$, CRP $<8 \mathrm{mg} / \mathrm{dL}$ for stable group. Model D:WBC $\geq 10,000 / \mathrm{mm}^{3}, \mathrm{CRP}>5 \mathrm{mg} / \mathrm{dL}$ for attack group; $W B C \geq 10,000 / \mathrm{mm}^{3}, C R P>5 \mathrm{mg} / \mathrm{dL}$ for stable group.

Abbreviations: CRP, C-reactive protein; MEM, modified exacerbation model; WBC, white blood cell.

\section{MEMs}

Table 2 summarizes the patient distribution in four MEMs. About $21 \%$ of subjects had an NLR value of $<3.54$ and $79 \%$ (845) had an NLR value of $\geq 3.54$.

ROC-AUC was used to assess "patients' NLR value" in all four attack models which were defined in the methods. In addition, NLR cutoff value was found according to ROC curves. The cutoff value of NLR was found to be 3.54 in the ROC curve analysis for each exacerbation model (Figure 3A-D). Model A had the greatest value of AUC (Figure 3). The sensitivity, specificity, negative predictive value (NPV), and positive predictive value (PPV) of an NLR of 3.54 for each exacerbation model were calculated and is summarized in Table 3. Model A was the best model for the diagnose of AECOPD.

The four MEMs showed significant correlation with an exacerbation at the cutoff value of NLR $\geq 3.54$, as summarized in Table 4.

\section{PBE and COPD exacerbation models}

During the study period, $5 \%(n=48)$ of the COPD patients had $\mathrm{PBE} \geq 2 \%$, and the remainder had non-eosinophilic COPD (PE $<2 \%)$.

\section{Discussion}

This study shows that the cutoff value of peripheral blood NLR in four MEMs, which were based on leukocyte and CRP values in COPD patients with CRF receiving LTOT and domiciliary NIMV, needs to be $\geq 3.54$ as an indicator of infectious COPD exacerbation. Nearly $5 \%$ of all the COPD patients with $\mathrm{CRF}$ had $\mathrm{PBE}(\geq 2 \%)$.

We generated AECOPD and modified COPD exacerbation models based on NLR values. Currently, the most applied algorithm for antibiotic treatment in AECOPD is the Anthonisen criteria that require an increase in at least one of the following symptoms: dyspnea, sputum volume, and sputum purulence. ${ }^{3,4}$ Although it is a simple application for the diagnosis of AECOPD and the decision to commence antibiotic therapy, it is subjective. In clinical practice, physicians require a more objective approach to initiate antibiotic therapy. In addition, severe COPD patients receiving LTOT and domiciliary NIMV may have these symptoms for nearly an entire year and the Anthonisen criteria may not be of much help for the physician.

In the acute exacerbation models, CRP values between 5 and $10 \mathrm{mg} / \mathrm{L}$ were included, as these levels have been detected in COPD patients in different conditions (ie, stable conditions, acute exacerbation, and existence of pneumonia) in previous studies. ${ }^{26-28}$ Calverley et $\mathrm{al}^{26}$ determined that pneumonia was more common in patients with severe dyspnea and in those with a baseline CRP level $>10 \mathrm{mg} / \mathrm{L}$. Hurst et $\mathrm{al}^{27}$ concluded that if the CRP value was above $8 \mathrm{mg} / \mathrm{L}$, it was accepted as AECOPD. Dickens et $\mathrm{al}^{28}$ showed that the baseline value of CRP for COPD patients was $5 \mathrm{mg} / \mathrm{L}$, and $3 \mathrm{mg} / \mathrm{L}$ for smokers, but in healthy nonsmokers it was $2 \mathrm{mg} / \mathrm{L}$. During stable conditions, some patients with COPD also have evidence of low-grade systemic inflammation with increased levels of inflammatory biomarkers such as CRP, fibrinogen, and leukocytes. ${ }^{14}$ Very recently, a few studies have shown NLR to better reflect the severity of community-acquired pneumonia than other inflammatory markers, including CRP. ${ }^{29-31}$ Besides this, the number of exacerbations was found to be higher in patients with high NLR levels than in patients with low levels. ${ }^{32}$ The cutoff value for NLR as an inflammatory indicator of COPD exacerbation was defined by Xiong et $\mathrm{al}^{32}$ as 3.3. In the current study, and based on the evaluation of NLR in patients with CRF due to the COPD, the cutoff value of NLR that indicated an exacerbation was identified as $\geq 3.54$, just greater than Xiong et al's study. Very recently, another study by Forget et al ${ }^{33}$ identified the normal NLR values in a healthy, non-geriatric adult population ( $\mathrm{n}=413)$; normal range was defined as $0.78-3.53$. The current study with an NLR cutoff value of 3.54 (NLR range 2.12-3.99) indicates that patients with severe COPD receiving LTOT and/or NIMV have higher NLR values than the upper normal level of healthy subjects. In a study by Taylan et al, ${ }^{34} 100$ patients who were admitted to the chest diseases ward due to AECOPD were evaluated in conjunction with their NLR, CRP, CBC, and sedimentation rates; NLR was found to be the most sensitive parameter for detecting acute exacerbation. The authors defined the NLR cutoff value for AECOPD as 3.26. ${ }^{34}$ Again, this value was very close to the cutoff value presented in the current study. 

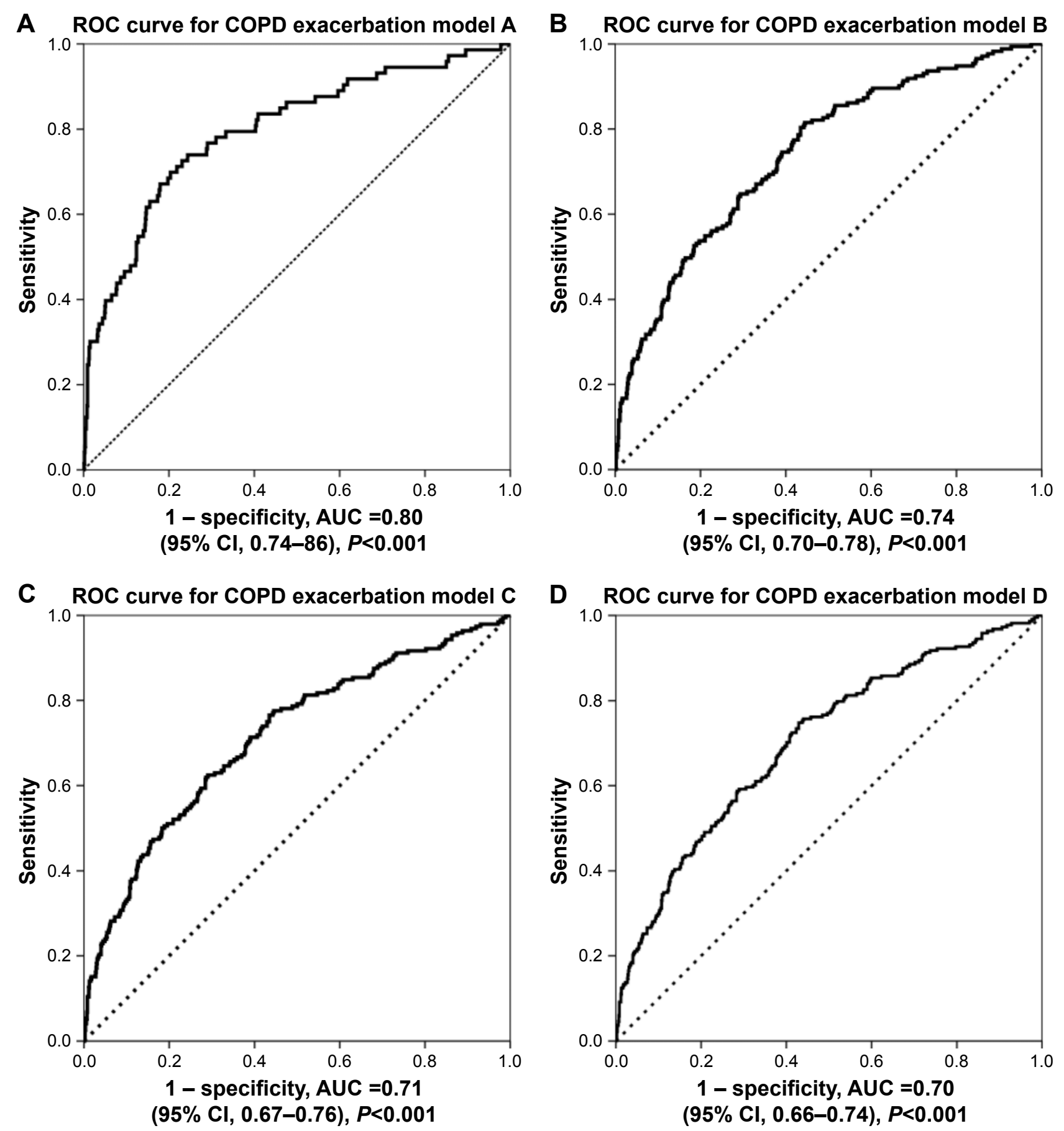

Figure 3 ROC curves, the optimal cutoff value, sensitivity, and specificity of NLR for MEMs (models A, B, C, D).

Notes: ROC-AUC was used to asses "patients' NLR value" in all four attack models. NLR cutoff value was found according to ROC curves. (A) The cutoff value, sensitivity, and specificity of NLR for exacerbation model A. (B) The cutoff value, sensitivity, and specificity of NLR for exacerbation model B. (C) The cutoff value, sensitivity, and specificity of NLR for exacerbation model C. (D) The cutoff value, sensitivity, and specificity of NLR for exacerbation model D. Diagonal segments are produced by ties.

Abbreviations: AUC, area under the curve; MEM, modified exacerbation model; NLR, neutrophil-to-lymphocyte ratio; ROC, receiver operating characteristic.

Lee et $\mathrm{a}^{35}$ compared AECOPD and a healthy control group and found that the NLR value correlated with the BODE index, modified Medical Research Council (mMRC) score, and 6-minute walk test. They determined that if the NLR value was $\geq 2.8$ it was a significant predictor for hospitalization. However, they did not evaluate the optimal cutoff value for
NLR to predict hospitalization. ${ }^{33}$ In the study by Duman et al, ${ }^{12}$ COPD patients who were readmitted to hospital during the 6 months post discharge had significantly higher NLR values (NLR 5.8 versus 4.9). Agca et a ${ }^{36}$ evaluated the readmission rate in an outpatient clinic for COPD patients, and an NLR $>4.50$ and with a non-eosinophilic exacerbation 
Table 3 The sensitivity and specificity of NLR $\geq 3.54$ value in MEMs

\begin{tabular}{lllll}
\hline & Specificity (\%) & Sensitivity (\%) & PPV & NPV \\
\hline Model A & 69 & 78 & 0.15 & 0.84 \\
Model B & 71 & 63 & 0.29 & 0.41 \\
Model C & 72 & 61 & 0.31 & 0.68 \\
Model D & 71 & 58 & 0.34 & 0.65 \\
\hline
\end{tabular}

Notes: Model A: WBC $\geq 12,000 / \mathrm{mm}^{3}$, CRP $>10 \mathrm{mg} / \mathrm{dL}$ for attack group; $W B C<12,000 / \mathrm{mm}^{3}, C R P<10 \mathrm{mg} / \mathrm{dL}$ for stable group. Model $B: W B C \geq 10,000 / \mathrm{mm}^{3}$, CRP $>10 \mathrm{mg} / \mathrm{dL}$ for attackgroup; $\mathrm{WBC}<10,000 / \mathrm{mm}^{3}, \mathrm{CRP}<10 \mathrm{mg} / \mathrm{dL}$ for stable group. Model C: WBC $\geq 10,000 / \mathrm{mm}^{3}, C R P>8 \mathrm{mg} / \mathrm{dL}$ for attack group; $\mathrm{WBC}<10,000 / \mathrm{mm}^{3}$, CRP $<8 \mathrm{mg} / \mathrm{dL}$ for stable group. Model D: WBC $\geq 10,000 / \mathrm{mm}^{3}, \mathrm{CRP}>5 \mathrm{mg} / \mathrm{dL}$ for attack group; $W B C \geq 10,000 / \mathrm{mm}^{3}, C R P>5 \mathrm{mg} / \mathrm{dL}$ for stable group.

Abbreviations: CRP, C-reactive protein; MEM, modified exacerbation model; NLR, neutrophil-to-lymphocyte ratio; NPV, negative predictive value; PPV, positive predictive value; WBC, white blood cell.

(peripheral blood eosinophils $<2 \%$ ) was found to indicate an increased risk of readmission in the first month. Although the current study did not evaluate readmission rates, the cutoff value for AECOPD was nearly at the critical NLR level for readmission as indicated in the Agca et al's study. Thus, COPD patients with CRF should be followed up closely.

In the current study, when NLR value was 3.54 and above, the predictive values were found to be lower for all four MEMs to diagnose AECOPD. The PPVs were lower in four exacerbation models, however, slightly increased from model A through model $\mathrm{D}$. The CRF outpatient clinic was designed to follow-up CRF patients discharged from the ICU with NIMV and LTOT. Patients were admitted to the outpatient clinic for routine control. Due to the outpatient clinics nature nearly all patients were in a clinically stable condition, this might be the reason of low PPVs. In the advance stage of COPD, patients had permanent respiratory symptoms such as cough, dyspnea and sputum. Under these circumstances, clinicians could easily misdiagnose the acute exacerbation in the severe stage of COPD. The lowest PPV and highest NPV were found in model A. These values might help clinicians when "NLR $<3.54$ " and peripheral blood eosinophil $<2 \%$ to decide not to prescribe antibiotics and anti-inflammatory drugs such as steroids. NLR values can guide physicians in treatment options of COPD and higher NPV can prevent overtreatment of AECOPD in model A. In models A, B, C, and $\mathrm{D}$, leukocytes and $\mathrm{CRP}$ values were designed to decrease through model A to D. Through models A-D, the sensitivity, specificity, and NPV were decreased. However, PPVs were slightly increased from model A to D. There is no precise definition of AECOPD, it is an important issue in daily practice. High negative predictive values can guide clinicians to rule out acute exacerbation. Through model D to A NPV were increased and, furthermore, the risk of over treatment and misdiagnose might have decreased .

\section{AECOPD and $2 \%$ peripheral blood eosinophils}

Previous studies showed that when the rate of PE increased, the severity of AECOPD decreased..$^{13,20,37}$ In AECOPD patients who were admitted to the ICU, ward, and outpatient clinic, $2 \%$ PBE rates were $10 \%, 25 \%$, and $43 \%$, respectively. ${ }^{12,13,38}$ In the study by Bafadhel et al, ${ }^{38} 25 \%$ eosinophilia was found in patients with AECOPD. In the current study, COPD patients with CRF receiving LTOT/NIMV had a lower percentage of peripheral blood eosinophils (nearly $5 \%$ ) than previous studies. Studies have indicated that the clinical outcomes of patients with eosinophilic exacerbations are better, and that the duration of their hospital stay and readmission rates are lower. ${ }^{12,20,37,38}$ Recent studies also showed that COPD patients with high blood eosinophil counts had lower consumption of systemic corticosteroid in exacerbation and greater responsiveness to inhaled corticosteroid (ICS) therapy. ${ }^{20,39}$ Thus, one could reason that eosinophilic COPD patients can be managed with anti-inflammatory drugs, while non-eosinophilic patients $(<2 \%)$ cannot, and this group of

Table 4 Ratio of the COPD patients with CRF according to the NLR and peripheral blood eosinophil count in MEMs

\begin{tabular}{|c|c|c|c|c|c|c|c|c|}
\hline & \multicolumn{2}{|l|}{ Model A } & \multicolumn{2}{|l|}{ Model B } & \multicolumn{2}{|l|}{ Model C } & \multicolumn{2}{|c|}{ Model D } \\
\hline & $\begin{array}{l}\text { Attack, } \\
\mathbf{N}(\%)\end{array}$ & $\begin{array}{l}\text { Stable, } \\
\mathbf{N}(\%)\end{array}$ & $\begin{array}{l}\text { Attack, } \\
\mathbf{N}(\%)\end{array}$ & $\begin{array}{l}\text { Stable, } \\
\text { N (\%) }\end{array}$ & $\begin{array}{l}\text { Attack, } \\
\text { N (\%) }\end{array}$ & $\begin{array}{l}\text { Stable, } \\
\text { N (\%) }\end{array}$ & $\begin{array}{l}\text { Attack, } \\
\mathbf{N}(\%)\end{array}$ & $\begin{array}{l}\text { Stable, } \\
\text { N (\%) }\end{array}$ \\
\hline \multicolumn{9}{|c|}{ Non-eosinophilic $<2 \%$} \\
\hline$N L R \geq 3.54$ & $54(78)$ & $300(32)$ & $106(66)$ & $248(29)$ & $113(63)$ & $24 \mid(29)$ & $122(60)$ & $232(29)$ \\
\hline NLR $<3.54$ & $15(22)$ & $649(68)$ & $55(34)$ & 609 (7I) & $66(37)$ & $598(71)$ & $82(40)$ & $582(72)$ \\
\hline \multicolumn{9}{|c|}{ Eosinophilic $\geq 2 \%$} \\
\hline NLR $<3.54$ & I (25) & $35(80)$ & $9(75)$ & $27(75)$ & $9(69)$ & $27(77)$ & $10(7 \mid)$ & $26(76)$ \\
\hline$N L R \geq 3.54$ & $3(75)$ & $9(20)$ & $3(25)$ & $9(25)$ & $4(3 I)$ & $8(23)$ & 4 (29) & $8(24)$ \\
\hline
\end{tabular}

Notes: Model A: WBC $\geq 12,000 / \mathrm{mm}^{3}, \mathrm{CRP}>10 \mathrm{mg} / \mathrm{dL}$ for attack group; WBC $<12,000 / \mathrm{mm}^{3}, \mathrm{CRP}<10 \mathrm{mg} / \mathrm{dL}$ for stable group. Model B: WBC $\geq 10,000 / \mathrm{mm} 3$, CRP $>10 \mathrm{mg} / \mathrm{dL}$ for attack group, WBC $<10,000 / \mathrm{mm}^{3}, \mathrm{CRP}<10 \mathrm{mg} / \mathrm{dL}$ for stable group. Model C: WBC $\geq 10,000 / \mathrm{mm}^{3}, \mathrm{CRP}>8 \mathrm{mg} / \mathrm{dL}$ for attack group; WBC $<10,000 / \mathrm{mm}^{3}, \mathrm{CRP}<8 \mathrm{mg} / \mathrm{dL}$ for stable group. Model D: WBC $\geq 10,000 / \mathrm{mm}^{3}$, CRP $>5 \mathrm{mg} / \mathrm{dL}$ for attack group; WBC $\geq 10,000 / \mathrm{mm}^{3}$, CRP $>5 \mathrm{mg} / \mathrm{dL}$ for stable group. Eosinophilic, peripheral blood eosinophil count $\geq 2 \%$; non-eosinophilic, peripheral blood eosinophil count $<2 \%$.

Abbreviations: CRF, chronic respiratory failure; CRP, C-reactive protein; MEM, modified exacerbation model; NLR, neutrophil-to-lymphocyte ratio; WBC, white blood cell. 
patients may be resistant to anti-inflammatory drugs. Noneosinophilic COPD patients' respiratory symptoms can only be controlled with oxygen and NIMV.

Percentage of PBE $(>2 \%)$ and NLR values together with symptoms may guide clinicians in treatment options such as steroids, antibiotics, or both as reported in previous studies which were conducted in our center with non-CRF COPD patients. ${ }^{12,34}$ Future prospective studies will help to decide precisely about the treatment response with the percentage of PBE $(>2 \%)$ and NLR values together with symptoms in AECOPD with or without CRF. These studies might guide to develop new treatment strategies on AECOPD.

The strength of this study lies in the fact that all the COPD patients with CRF were followed-up after ICU discharge by the same ICU team, which consisted of intensivists and pulmonologists, in an ICU outpatient clinic, due to usage of domiciliary LTOT and/or NIMV to prevent readmission.

There were some limitations. First, it was a retrospective, single-center study. Nonetheless, it provides crucial clinical information due to the large sample size and specific patient groups. Data were collected electronically from the hospital online database to prevent incorrect and missed data entry. Second, the study was undertaken using only COPD patients with CRF and the results were not generalized. These results may be helpful for physicians managing COPD patients with CRF during their follow-up period.

\section{Conclusion}

Awareness of AECOPD in patients with CRF receiving LTOT and NIMV at home can be crucial when assessing early treatment options to prevent readmission. Objectively, NLR and PBE $(>2 \%)$ can be used to support the diagnosis of AECOPD, together with patients' symptoms. In the cases of an acute exacerbation, PBE and NLR value $\geq 3.54$ can be useful for assessing treatment options in COPD patients with CRF requiring LTOT/NIMV.

In the presence of respiratory symptoms, noneosinophilic and NLR values below the 3.54 group should be checked for existing treatment and patients' compliance before the decision on prescribing anti-inflammatory and antibiotic medications. Careful consideration before prescribing steroids and antibiotics should be performed to these COPD group (probably not required). Future studies are needed to clarify treatment choices for AECOPD based on the identification of the exacerbation as neutrophilic or eosinophilic.

\section{Acknowledgments}

The authors thank Dr Gokay Gungor and Dr Ozlem Yazıoğlu Moçin for participating in the design of the study and
Dr Sharon Forsyth for editing the manuscript. The abstract of this paper was presented at the 2016 ERS annual meeting as a oral presentation with interim findings. The abstract was published in "Poster Abstracts" in ERJ, September 1, 2016; vol 48, issue suppl 60, OA1785. The actual paper, however, has never been published. The English in this document has been checked by at least two professional editors, and both are native speakers of English (http://www. biomedicalediting.com).

\section{Author contributions}

All the authors have made substantial contributions to conception and design, or acquisition of data, or analysis and interpretation of data; have been involved in drafting the manuscript or revising it critically for important intellectual content; and approved the final version of the manuscript. EAT carried out data collection, analysis, and interpretation of data, participated in the design of the study, and contributed to writing and revising the study. ZK carried out data collection and interpretation of data, participated in the design of the study, contributed to writing and revising the study, helped to get ethical approval and draft the manuscript, and performed statistical analysis. CS carried out data collection, analysis, and interpretation of data, participated in the design of the study, contributed to writing and revising the study, and helped to get ethical approval and draft the manuscript. EA carried out data collection, analysis, and interpretation of data, participated in the design of the study, and contributed to writing the study. SG carried out data collection, analysis, and interpretation of data and participated in the design of the study. NC carried out data collection, analysis, and interpretation of data and participated in the design of the study. II carried out data collection, analysis, and interpretation of data and participated in the design of the study. DY carried out data collection and interpretation of data and participated in the design of the study. BO carried out data collection, analysis, and interpretation of data and participated in the design of the study. NA carried out data collection, analysis, and interpretation of data, participated in the design of the study, and contributed to revising the study.

\section{Disclosure}

All the authors who contributed to the study design do not have any industry relationships for the past 2 years. The manuscript has been read and approved by all the authors, and each author believes that the manuscript represents honest work. The authors report no conflicts of interest in this work. 


\section{References}

1. Brightling CE. Biomarkers that predict and guide therapy for exacerbations of chronic obstructive pulmonary disease. Ann Am Thorac Soc. 2013;10(suppl):S214-S219.

2. White AJ, Gompertz S, Stockley RA. Chronic obstructive pulmonary disease. 6: the aetiology of exacerbations of chronic obstructive pulmonary disease. Thorax. 2003;58(1):73-80.

3. Global Initiative for Chronic Obstructive Lung Disease [home page on Internet]. Global Strategy for Diagnosis, Management, and Prevention of COPD (updated 2012). Available from: http://www.goldcopd.org. Accessed August 25, 2016.

4. Anthonisen NR, Manfreda J, Warren CP, et al. Antibiotic therapy in exacerbation of COPD. Ann Intern Med. 1987;106:196-204.

5. Perez-Bogerd S, Fremault A, Decramer M, Janssens W. Criteria for antibiotic therapy in acute exacerbations of COPD. Am J Respir Crit Care Med. 2010;182(9):1207.

6. Dransfield MT, Bailey W, Crater G, Emmett A, O’Dell DM, Yawn B. Disease severity and symptoms among patients receiving monotherapy for COPD. Prim Care Respir J. 2011;20(1):46-53.

7. Brusse-Keizer MG, Grotenhuis AJ, Kerstjens HA, et al. Relation of sputum colour to bacterial load in acute exacerbations of COPD. Respir Med. 2009;103(4):601-606.

8. Chen H, Wang Y, Bai C, Wang X. Alterations of plasma inflammatory biomarkers in the healthy and chronic obstructive pulmonary disease patients with or without acute exacerbation. J Proteomics. 2012; 75(10):2835-2843.

9. Dahl M, Tybjaerg-Hansen A, Vestbo J, Lange P, Nordestgaard BG. Elevated plasma fibrinogen associated with reduced pulmonary function and increased risk of chronic obstructive pulmonary disease. Am J Respir Crit Care Med. 2001;164(6):1008-1011.

10. Thomsen M, Dahl M, Lange P, Vestbo J, Nordestgaard BG. Inflammatory biomarkers and comorbidities in chronic obstructive pulmonary disease. Am J Respir Crit Care. 2012;286(10):982-988.

11. Günay E, Sarınç Ulaşlı S, Akar O, et al. Neutrophil-to-lymphocyte ratio in chronic obstructive pulmonary disease: a retrospective study. Inflammation. 2014;37(2):374-380.

12. Duman D, Aksoy E, Agca MC, et al. The utility of inflammatory markers to predict readmissions and mortality in COPD cases with or without eosinophilia. Int J Chron Obstruct Pulmon Dis. 2015;10: 2469-2478.

13. Saltürk C, Karakurt Z, Adiguzel N, et al. Does eosinophilic COPD exacerbation have a better patient outcome than non-eosinophilic in the intensive care unit? Int J Chron Obstruct Pulmon Dis. 2015;10: 1837-1846.

14. Gan WQ, Man SFA, Senthilselvan A, Sin DD. Association between chronic obstructive pulmonary disease and systemic inflammation: a systematic review and a meta-analysis. Thorax. 2004;59(7):574-580.

15. Saetta M, Di Stefano A, Maestrelli P, et al. Airway eosinophilia in chronic bronchitis during exacerbations. Am J Respir Crit Care Med. 1994;150(6 pt 1):1646-1652.

16. Saha S, Brightling CE. Eosinophilic airway inflammation in COPD. Int J Chron Obstruct Pulmon Dis. 2006;1(1):39-47.

17. Eltboli O, Bafadhel M, Hollins F, et al. COPD exacerbation severity and frequency is associated with impaired macrophage efferocytosis of eosinophils. BMC Pulm Med. 2014;14:112.

18. Bafadhel M, Davies L, Calverley PM, Aaron SD, Brightling CE, Pavord ID. Blood eosinophil guided prednisolone therapy for exacerbations of COPD: a further analysis. Eur Respir J. 2014;44: 789-791.

19. Bafadhel M, McKenna S, Terry S, et al. Acute exacerbations of chronic obstructive pulmonary disease: identification of biologic clusters and their biomarkers. Am J Respir Crit Care Med. 2011;184(6): $662-671$.

20. Serafino-Agrusa L, Scichilone N, Spatafora M, Battaglia S. Blood eosinophils and treatment response in hospitalized exacerbations of chronic obstructive pulmonary disease: a case-control study. Pulm Pharmacol Ther. 2016;37:89-94.
21. Qaseem A, Wilt TJ, Weinberger SE, et al; American College of Physicians; American College of Chest Physicians; American Thoracic Society; European Respiratory Society. Diagnosis and management of stable chronic obstructive pulmonary disease: a clinical practice guideline update from the American College of Physicians, American College of Chest Physicians, American Thoracic Society, and European Respiratory Society. Ann Intern Med. 2011;155(3):179-191.

22. Kocabaş A, Atış S, Çöplü L, et al. Kronik Obstrüktif Akciğer Hastalığg (KOAH) Koruma, Tanı ve Tedavi Raporu [Prevention, diagnose and treatment report of chronic obstructive pulmonary disease (COPD)]. Turk Thorac J. 2014;15(suppl 2):19-25.

23. Garpestad E, Brennan J, Hill NS. Noninvasive ventilation for critical care. Chest. 2007;132(2):711-720.

24. Consensus Conference. Clinical indications for noninvasive positive pressure ventilation in chronic respiratory failure due to restrictive lung disease, COPD, and nocturnal hypoventilation - a consensus conference report. Chest. 1999;116(2):521-534.

25. Standardization of spirometry, 1994 update. American Thoracic Society. Am J Respir Critical Care Med. 1995;152(3):1107-1136.

26. Calverley PM, Stockley RA, Seemungal TA, et al; Investigating New Standards for Prophylaxis in Reduction of Exacerbations (INSPIRE) Investigators. Reported pneumonia in patients with COPD: findings from the INSPIRE study. Chest. 2011;139(3):505-512.

27. Hurst JR, Donaldson GC, Perera WR, et al. Use of plasma biomarkers at exacerbation of chronic obstructive pulmonary disease. Am J Respir Crit Care Med. 2006;174(8):867-874.

28. Dickens JA, Miller BE, Edwards LD, et al; Evaluation of COPD Longitudinally to Identify Surrogate Endpoints (ECLIPSE) Study Investigators. COPD association and repeatability of blood biomarkers in the ECLIPSE cohort. Respir Res. 2011;12:146.

29. Iliaz S, Iliaz R, Ortakoylu G, Bahadir A, Bagci BA, Caglar E. Value of neutrophil/lymphocyte ratio in the differential diagnosis of sarcoidosis and tuberculosis. Ann Thorac Med. 2014;9(4):232-235.

30. de Jager CP, van Wijk PT, Mathoera RB, de Jongh-Leuvenink J, van der Poll T, Wever PC. Lymphocytopenia and neutrophil-lymphocyte count ratio predict bacteremia better than conventional infection markers in an emergency care unit. Crit Care. 2010;14(5):R192.

31. de Jager CP, Wever PC, Gemen EF, et al. The neutrophil-lymphocyte count ratio in patients with community-acquired pneumonia. PLoS One. 2012;7(10):e46561.

32. Xiong W, Xu M, Zhao Y, Wu X, Pudasaini B, Liu JM. Can we predict the prognosis of COPD with a routine blood test? Int J Chron Obstruct Pulmon Dis. 2017;12:615-625.

33. Forget P, Khalifa C, Defour JP, Latinne D, Van Pel MC, De Kock M. What is the normal value of the neutrophil-to-lymphocyte ratio? BMC Res Notes. 2017;10(1):12.

34. Taylan M, Demir M, Kaya H, et al. Alterations of the neutrophillymphocyte ratio during the period of stable and acute exacerbation of chronic obstructive pulmonary disease patients. Clin Respir J. 2017; 11(3):311-317.

35. Lee SJ, Lee HR, Lee TW, et al. Usefulness of neutrophil to lymphocyte ratio in patients with chronic obstructive pulmonary disease: a prospective observational study. Korean J Intern Med. 2016;31(5): 891-898.

36. Agca MC, Aksoy E, Duman D, et al. Does eosinophilia and neutrophilto-lymphocyte ratio effect hospital re-admission in cases of COPD exacerbation? Am J Respir Crit Care Med. 2016;193:A6240.

37. Kang HS, Rhee CK, Kim SK, et al. Comparison of the clinical characteristics and treatment outcomes of patients requiring hospital admission to treat eosinophilic and neutrophilic exacerbations of COPD. Int $J$ Chron Obstruct Pulmon Dis. 2016;11:2467-2473.

38. Bafadhel M, Greening NJ, Harvey-Dunstan TC, et al. Blood eosinophils and outcomes in severe hospitalized exacerbations of COPD. Chest. 2016;150(2):320-328.

39. Cheng SL, Lin CH. Effectiveness using higher inhaled corticosteroid dosage in patients with COPD by different blood eosinophilic counts. Int J Chron Obstruct Pulmon Dis. 2016;11:2341-2348. 
International Journal of COPD

Dovepress

\section{Publish your work in this journal}

The International Journal of COPD is an international, peer-reviewed journal of therapeutics and pharmacology focusing on concise rapid reporting of clinical studies and reviews in COPD. Special focus is given to the pathophysiological processes underlying the disease, intervention programs, patient focused education, and self management protocols.

This journal is indexed on PubMed Central, MedLine and CAS. The manuscript management system is completely online and includes a very quick and fair peer-review system, which is all easy to use. Visit http://www.dovepress.com/testimonials.php to read real quotes from published authors.

Submit your manuscript here: http://www.dovepress.com/international-journal-of-chronic-obstructive-pulmonary-disease-journal 